Universidad Nacional de La Plata.

Facultad de Humanidades y Ciencias de la Educación.

Departamento de Educación Física

\title{
El género debajo de la colchoneta. Conversaciones sobre cuerpo(s) en Educación Física
}

\author{
Gender under the mat. Conversations about body/bodies in \\ Physical Education \\ María Flavia Cuello \\ mariaflaviacuello@gmail.com \\ Universidad Provincial de Córdoba, Argentina \\ Alicia Soledad Martínez \\ melquiades69@hotmail.com \\ Universidad Provincial de Córdoba, Argentina
}

Recepción: 31 Julio 2020

Aprobación: 27 Octubre 2020

Publicación: 09 Octubre 2020

Cita sugerida: Cuello, M. F. y Martínez, A. S. (2020). El género debajo de la colchoneta. Conversaciones sobre cuerpo(s) en Educación Física. Educación Física y Ciencia, 22(4), e153. https://doi.org/10.24215/23142561e153

\begin{abstract}
Resumen: El siguiente artículo refiere a un análisis de una experiencia de taller virtual, al que fuimos invitadas para conversar acerca de la Educación Física y el género. Pareciera que en algunos espacios de la Educación Física, hablar de género y sexualidades es una temática en la que suscita el silencio y el ocultamiento. La intención de pensar lo oculto del género en la Educación Física nos llevó a preguntarnos por el modo de mirar los cuerpos, que aparece en este campo disciplinar. A partir de los diálogos con lxs participantes de la charla: "El género debajo de la colchoneta. Conversaciones sobre cuerpo(s) en Educación Física”, emergen elementos que van dando cuenta de los modos de mirar lxs cuerpos y nos da lugar a revisitar las zonas en las que se cristaliza el saber de la disciplina y los recorridos, rasgos y trazos teóricos que fueron construyendo la manera de mirar el cuerpo en la pedagogía corporal, para pensar los límites de una posible educación sexual en clave de Educación Física.
\end{abstract}

Palabras clave: Educación Física, Analítica del cuerpo, Perspectiva de género, Campo disciplinar.

\begin{abstract}
: he following article refers to an analysis of a virtual workshop experience, to which we were invited to talk about Physical Education and gender. It seems that in some areas of Physical Education, talking about gender and sexualities is a theme in which it elicits silence and concealment. he intention of thinking about the hidden nature of gender in Physical Education led us to ask ourselves about the way of looking at bodies that appears in this disciplinary field. From the dialogues with the participants in the talk: " he gender under the mat. Conversations about body ( $s$ ) in Physical Education", elements emerge that account for these modes and give us the opportunity to revisit the areas in which the knowledge of the discipline is crystallized and the routes, theoretical traits and lines that were building the way of looking at the body in body pedagogy, to think the limits of a possible sexual education in key of the Physical Education.
\end{abstract}

Keywords: Physical Education, Body Analytics, Gender perspective, Disciplinary field.

\section{Introducción.}

Este artículo se desprende del análisis de una instancia de taller virtual para un Instituto de Formación Docente de Educación Física, a la que hemos sido invitadas para charlar acerca cuestiones sobre Género en la Educación Física. 
En diálogos con lxs docentes a cargo de este ciclo de charlas, aparece como discurso, la sensación común de que todo lo que tenga que ver con género y sexualidades en Educación Física, lo metemos debajo de la colchoneta $^{l}$, como si al ocultarse estas cuestiones, evitamos la discusión al respecto. En este sentido, estos diálogos fueron delineando nuestro interés al momento de pensar la charla y definieron el título de este artículo.

En estudios vinculados con los sentidos de género en la formación docente de Educación Física ${ }^{2}$, pudimos reconocer una escisión entre lo relacionado con el género y la Educación Física, como si pertenecieran a campos diferentes, o bien como plantearon algunxs estudiantes de cursos avanzados de la carrera -interlocutores-, el género y la Educación Física no tienen nada que ver ${ }^{3}$.

Esta concepción que lleva al conocimiento de los cuerpos y los géneros comprendidos en una suerte de escisión responde a construcciones discursivas de y sobre el cuerpo que históricamente constituyeron las tradiciones en el campo disciplinar de Educación Física. Siendo el modo de explicarlo y concebirlo, no hay posibilidades de otro cuerpo que esa escisión, teórica. Según Foucault (Donda, 2014) estas operaciones sobre nuestro cuerpo, producen la sustracción del mismo, nos entendemos como un cuerpo, entendemos a nuestro cuerpo desde tales concepciones y explicaciones.

Pensar los ocultamientos del género -y sus ignorancias-, tanto como enfoque teórico o bien expresiones de la subjetividad, nos llevó a mirar las concepciones, en tanto imágenes, de cuerpo que aparecen en estudiantes y docentes de Educación Física a manera de código común del lenguaje en los espacios de formación y como saber disciplinar.

En este artículo proponemos reconocer los modos "comunes" de mirar los cuerpos en la formación docente de Educación Física a partir de una experiencia de taller, para dar cuenta de cómo estos modos, -que no sólo hacen a un cuerpo a través de la mirada, sino que constituyen representaciones comunes sobre éstos-, ocultan rasgos y atributos de su sexualidad. Las imágenes compartidas muestran un cuerpo educado y modelado, a partir de técnicas y prácticas corporales vinculadas con las habilidades y capacidades, entendidas como las formas adecuadas de moverse, las maneras "a imitar" para conseguir logros a nivel motriz y deportivo. Estas representaciones iconográficas habilitan a su vez, de acuerdo con Galak (2017) discursos políticos y sentidos estéticos sobre los cuerpos. Al disponer la mirada en las analíticas del cuerpo de la modernidad, se obtura la posibilidad de pensar a los cuerpos sexuados, produciendo un enfoque de género ignorado.

\section{Desarrollo.}

\section{La charla-taller y los modos de mirar los cuerpos.}

Planteamos nuestro taller a modo de conversación, que comenzó con una pregunta, referida al título con el que decidimos encararla, 
¿qué les generó el título de la charla "El género debajo de la colchoneta. Conversaciones sobre cuerpo(s) en Educación Física"?, luego de un pequeño silencio, Mercedes ${ }^{4}$, propone, que si no surge ninguna sensación al respecto, podrían pensar en lo que imaginan cuando leen el título. Las intervenciones comenzaron a aparecer tímidamente en el chat, una docente escribió educación igualitaria para niños y niñas, otra responde que le generó inquietud y curiosidad. Celeste, una estudiante planteó que le llamó la atención debajo de la colchoneta y Agustina -otra estudiantedice actividades relacionadas a la gimnasia artística, Patricia dice me gustó la idea de género 'debajo' de la colchoneta y pensar las ideas de género. A raíz de lo que fue surgiendo entre lxs participantes, comenzamos la charla contando que el título del taller surgió a raíz de ver, en nuestros distintos trayectos docentes, que las problemáticas de género en Educación Física, se metían "debajo de la colchoneta", y a partir de ahí, nuestra intención era reflexionar acerca de los modos en que miramos los cuerpos en Educación Física. En este sentido, la pregunta que orientó este taller fue ¿Cómo es el cuerpo que miramos, cuando miramos los cuerpos en Educación Física?A partir de esa pregunta, les comentamos la consigna a lxs participantes, contándoles que mostraremos algunas imágenes y que nos interesaba nos comentaran en el chat "¿qué ven cuando ven esas imágenes?".

De esta manera el taller se organizó en dos etapas, en la primera se trabajó con la consigna y la presentación de tres grupos de imágenes vinculadas con prácticas corporales y en la segunda etapa propusimos mirar el cuerpo con atributos ${ }^{5}$ vinculado con el eje de sexualidad y de derechos humanos que propone los lineamientos de Educación Sexual Integral.

El primer grupo estaba compuesto por imágenes escolares propias de la Educación Física, tales como niñxs saltando sobre una fila de aros, o bien imágenes de niñxs corriendo en un patio, jóvenes saltando sobre una hilera de minivallas.

Lxs participantes fueron escribiendo en el chat algunas palabras, preparación, confianza, movimientos, movimientos corporales, algunas actividades para varones otras para niñas, mucha energía, liberación y cooperación, diversidad, ejercicio, imaginación, niños haciendo uso de sus cuerpos, libertad, cuerpos flexibles, libertad de movimiento, diversión, disfrutar de lo que están haciendo. Dante -un estudiante- aporta, distintas identidades que se manifiestan a través del movimiento, contacto físico estrecho entre las niñas.

El segundo grupo estaba compuesto por imágenes vinculadas con el deporte olímpico. En esta línea de imágenes se presentaron a un gimnasta realizando la cruz de hierro, en anillas, una imagen de Michael Phelps realizando la respiración y el recobro de brazos en el estilo pecho y una gimnasta china realizando una paloma en una serie de suelo de gimnasia rítmica deportiva.

Lxs participantes fueron respondiendo en el chat, lo que consideraban que veían en las imágenes, con este segundo grupo surgieron los siguientes términos resistencia, flexibilidad, técnica, elasticidad, equilibrio, 
fuerza, diferentes tipos de gimnasia, much a técnica, concentración, progreso y superación, cuerpos rigidos, habilidad, excelencia, constancia, trabajo, estructuras estereotipadas, profesionales que trabajan a la par, géneros, cuerpos disciplinados, coordinación, disciplina.

A este grupo de imágenes le siguen otras, vinculadas con progresiones de técnicas deportivas: progresión del lanzamiento de básquetbol, la toma de la fase de vuelo de la técnica de carrera, incluímos una pregunta "¿qué tipo de cuerpo creen que cumple con esas condiciones que plantean las imágenes?" y lxs participantes respondieron en el chat, que en el tercer grupo de imágenes veían: fuerza, potencia, vigor, velocidad, coordinación, saltos, mucho entrenamiento, objetivos a lograr, metodologias, excelencias, sincronia de movimientos, gesto técnico completo, capacidades condicionales y coordinativas, mecanización, manejo de los elementos.

En esta línea, fuimos tomando los distintos términos que nos dieron lxs participantes para introducir en nuestra charla las recurrencias y el lenguaje común que los y las docentes de Educación Física manejamos cuando nos referimos a lxs cuerpos. Es necesario agregar, que la fluidez de palabras que se escribían en el chat fue más dinámica e intensa en los dos últimos grupos de imágenes. Siendo la pista a seguir para revisar los elementos importantes que surgieran en la charla.

Seguidamente al intercambio producido desde los diferentes grupos de imágenes mostradas, abrimos las siguientes preguntas: “¿por qué sería necesario preguntarse por el género dentro de la Educación Física?, ¿qué hace que nos preguntemos por el género en Educación Física? y ¿qué hace que esta pregunta no emerja como necesidad en la formación docente?".

La tradición o especie de "código común" en la enseñanza de la E.F. parece continuar indicando que: de lo que nos teníamos que ocupar era de estos gestos, estas técnicas y estas construcciones que reflejan los patios escolares, las instancias de preparación física o estas propuestas deportivas, por eso la pregunta sobre los cuerpos y las cuerpas (dirían ciertas reflexiones), tenía que ver con ¿cómo encontramos esos cuerpos dentro de la Educación Física? y ¿cómo los encontramos pensados y teorizados en los mismos textos con los que nos preparamos para ser profes?

A raíz de lo que íbamos proponiendo en nuestro diálogo, preguntamos: "¿qué tienen que ver este grupo de imágenes presentadas, con el género?”. Si al presentarlas, aparecían con fuerza otros conceptos y no necesariamente aquellos que pueden reconocer cuerpos sexuados o cuerpos generizados, "la diversidad, la sexualidad o el género, aparentemente no aparecen". Predominan en nuestro lenguaje común, otros conceptos referidos a lxs cuerpos, que tienen que ver con el discurso del enfoque anatómico - fisiológico, en clave biomecánica. En la charla aclaramos que si bien este no es el único enfoque, de alguna manera cuando estamos en el ambiente o en el contexto de la Educación Física pareciera mucho más fácil y que todo el mundo comprende, lo que decimos cuando decimos habilidades motrices, capacidades coordinativas, capacidades condicionales, gestos técnicos, progresiones, como un lenguaje común en nuestra disciplina y eso tiene que ver con que hay toda una 
construcción de un discurso sobre ese cuerpo, sobre ese enfoque de cuerpo $y$ sobre los cuerpos -porque los discursos pueden performar esos cuerpos y sus prácticas-vinculado con este enfoque analítico de cuerpo en clave biomecánica.

Antes de pensar el cuerpo en tanto huesos, articulaciones y músculos, nos enseñaban los planos y los ejes del cuerpo. Conceptos que tienen un sentido en todo nuestro recorrido de formación. Esto no aparece de la nada o por casualidad, que de repente los y las docentes de Educación Física hablamos un lenguaje común y que nosotros lo tomamos como "el enfoque" (como guía metodológica y pedagógica), ¿cómo ingresan estos términos en la formación docente y cómo ingresan en lo escolar?

Estas reflexiones nos llevan a pensar sobre la analítica del cuerpo, lo que se configuró como la forma de mirar el cuerpo, el modo legitimidado de mirar los cuerpos a partir de la modernidad, y que se inscribió en la Educación Física, constituyendo la mirada que solicita la técnica, o bien la mirada técnica que requiere la profesionalización de la tarea.

En la charla presentamos la inquietud de ¿en qué momento yo miro mi cuerpo y veo ese plano, ese eje, en qué momento de mi realidad y pensando los patios de la Educación Física?, ¿en qué momento me veo así de fragmentada, distribuida en partes, en sectores, en lugares? pensando un cuerpo que está dividido claramente entre funciones y roles. En este sentido continuamos reflexionando con la pregunta: ¿Cuándo se instala esa hegemonia, por qué se instala esa mirada sobre el cuerpo, esa forma de mirar y ver los cuerpos, de ubicarlos en los espacios? y en particular referimos a esto que Foucault menciona como politica, analitica del cuerpo, que se presenta fuertemente en el siglo XIX, siendo como una alianza epistémica, porque esto es una función epistémica -aclara Flavia-algo hace que pensemos de esa manera, y esta alianza es funcional, -continúaa una visión biológica pero Foucault dice no es meramente biológico, lo biológico es sólo un indicador, acá hay algo más que tiene que ver con mirar cómo socialmente empezamos a administrar los cuerpos, y cuando Foucault incorpora esta palabrita de la administración, lo piensa como politica, una biopolitica, es decir, cómo administramos las vidas de estos cuerpos.

$Y$ desde alli va a enunciar que hay una estructura politica para pensar espacio y tiempo. Que en realidad lo que la modernidad produjo son conceptos para pensar las coordenadas de espacio y tiempo, que esto es cartesiano, del 1600 y aparece en esas coordenadas de espacio y tiempo, donde emergen los cuerpos. Y esos cuerpos que emergen, no emergen de cualquier manera, emergen traducidos en discursos, traducidos en prácticas, va a decir Foucault "traducido en técnicas" -explica Flavia-.

Las técnicas son las que colaboran y ayudan a la episteme a sostenerse, entonces cuando miramos la Educación Física justamente lo que vemos es, tanta bibliografía, tanto trabajo y tanto esfuerzo por construir y sostener esas técnicas que hace que realmente pensemos al cuerpo bajo esta lógica hegemónica. Y mirar qué atributos del cuerpo quedan fuera de estas lógicas, quedan fuera de estos esquemas, algunos ni siquiera pueden ingresar. Cuando veía recién las imágenes y miraba sus chats, por ejemplo, no habia mención a las diversidades funcionales, lo que puede ser una diversidad 
morfológica, no habia una referencia a eso, habia justamente esta referencia a las técnicas, al adiestramiento, a lo coordinativo, entonces cuando miramos el cuerpo ¿vemos eso?, ¿vemos la coordinación?, ¿vemos la forma de pararse? vemos esa materialidad de una condición epistémica que fue planteada en un siglo atrás y que se traduce en esta práctica, que es la práctica de la construcción y de un efecto que es la operación de un mecanismo, de administrar los cuerpos para que los cuerpos rindan. Porque Foucault va a decir, acá no importa que el cuerpo sea obediente, lo que importa es que el cuerpo rinda. Y para que el cuerpo rinda tiene que mostrarse y administrarse a partir de lógicas de espacio y de tiempo. Por eso hay lógicas de tiempo, para cuando el cuerpo tiene que estar despierto, para cuando tiene que estar dormido y descansar; hay lógicas de la administración del espacio que es como desplegar y como mirar, además es una lógica muy de la frontalidad, de la modernidad europea que impone la frontalidad y esa frontalidad es a su vez, como mencionaron en algunos de sus comentarios, es binaria. Una frontalidad del trato corporal en donde la experiencia está signada por esa administración temporo-espacial en donde se sustrae y donde se ve al cuerpo como objeto y no sólamente al cuerpo sino al sujeto y a los procesos de subjetivación incorporados o vistos en estas lógicas y en estas coordenadas de administración de espacio-tiempo. Entonces sucede algo fuerte, que tiene que ver con la sustracción de lo esencial, la sustracción subjetiva, la sustracción en términos de una heteronormatividad que ya nos hace borrar si estamos viendo cuerpos diferentes, diversos, sino que lo que estamos viendo es eso, flexibilidad, coordinación.

\section{La analítica del cuerpo.}

A nuestro entender, la analítica del cuerpo se expone como elemento que nuclea a los discursos sobre el cuerpo en Educación Física. En torno a esta última reflexión que surge a partir del taller, es necesario remitirnos al análisis que entrama la ciencia moderna sobre su matriz productora de discursos, como "efectos de verdad" sobre lxs sujetos. En tal sentido, la Educación Física se nutre de las preguntas de las ciencias modernas para explicar a lxs sujetos y a lxs cuerpos, y se configura como disciplina efectora de prácticas corporales que contienen un supuesto saber acerca de lxs mismos. La tensión transcurre en torno a su ambigüedad instrumental, en tanto discurso ordenador de saberes sobre el sujetx y dispositivo que posibilita la aplicabilidad de prácticas para lxs cuerpos. Tal ambigüedad ensambla discursos de "otros" y sus efectos en torno a la producción de técnicas para constituir identidades y subjetividades en su propósito escolarizante. (Rodríguez, 2015)

Siguiendo a Foucault (2002) el cuerpo es un fragmento de espacio ambiguo cuya espacialidad se articula sobre el espacio de las cosas. En la modernidad surge un tipo de análisis que se aloja en el espacio del cuerpo, mediante el estudio de la percepción, los mecanismos sensoriales y los esquemas neuromotores, y la estética corporal que determina sus formas por sus contenidos empíricos. Aparece la dietética del cuerpo que define el uso de los placeres, proponiendo cierta manera de ocuparse del cuerpo. 
Estos mecanismos de poder, indagan los cuerpos, los gestos y los comportamientos. La historia del control social del cuerpo muestra cómo se pasó del cuerpo como superficie de inscripción de penas y castigos, al cuerpo como lo que debe ser corregido y reformado en el siglo XIX. Se constituye un arte de los efectos sobre el cuerpo.

En las sociedades modernas el cuerpo aparece como superficie de análisis. Siguiendo a Foucault la invención de una nueva anatomía política, responde a una multiplicidad de procesos menores, de orígenes diferentes, diseminados, que coinciden y se repiten, se apoyan unos sobre otros, entran en convergencia y dibujan un método general, una estructura. Estos diseños constituyeron una forma (productiva) ${ }^{6}$ de concebir el cuerpo que se articulaba con una nueva forma de administrar el tiempo (Foucault, 1998 en Donda, 2014).

La primera operación de la disciplina es la constitución de cuadros vivos que transforman las multitudes confusas en multiplicidades ordenadas. Se trataba de organizar lo múltiple, de imponer un orden. La administración de espacio y de tiempo declina en que el objeto dirigido en tales coordenadas será el cuerpo mismo del sujeto,

A decir de Foucault el cuerpo se convierte en un bien social, en un objeto de una apropiación colectiva y útil. Nace un arte del cuerpo donde se vuelve más obediente cuanto más útil sea. El cuerpo entra en una maquinaria que lo explora, lo desarticula y lo recompone. No se trata de obtener cuerpos que hagan lo que se desea, sino que funcionen como se quiera, con las técnicas, la rapidez y la eficacia que se pretende de ellos (Foucault, 1964 en Castro, 2011).

El empleo del tiempo es un elemento clave para lograr el control de un cuerpo en actividad. Si bien es una herencia monástica, en la modernidad el tiempo se torna seriado-cronometrado-programado, regula los actos, la descomposición del cuerpo en partes, de sus miembros, de las articulaciones y de los movimientos. Un buen empleo del cuerpo es un buen empleo del tiempo.

A su vez, la aparición de esta noción de tiempo métrico vinculado con la eficacia y la rapidez, tiene su anclaje en un orden mayor, que comprende a la organización de la génesis. Siguiendo a Foucault (2002) aparece el desarrollo de una nueva técnica para ocuparse de las existencias singulares, para regir las relaciones del tiempo, de los cuerpos y de las fuerzas. Se conforma un tiempo lineal, cuyos momentos se integran unos a otros y se orientan hacia un punto terminal y estable. Un tiempo evolutivo que fija sus agujas en la noción de desarrollo y de progreso. Estos "descubrimientos" modernos, le otorgan al sujeto la posibilidad de pensarse como hacedor de su historia, de describir o narrar su génesis como toma de conciencia del pasado-presente-futuro. Esta noción sitúa el ordenamiento social en clave de naturaleza: crecer, madurar, evolucionar; lo que socialmente se entiende como progreso-desarrollo, productividad.

El cuerpo se ha convertido en el verdadero objeto de la política moderna, no existe como un artículo biológico o material sino dentro y a través de un sistema político, siendo: cuerpo viviente, cuerpo individual y cuerpo social. Para esto van a trabajar las disciplinas. Las disciplinas tienen 
la tarea de fabricar una individualidad dotada de cuatro características: celular, orgánica, genética y combinatoria. (Castro, 2011)

En el siglo XIX proliferan los elementos ortopédicos, bajo la forma de dispositivos que garantizan el enderezamiento y adiestramiento del cuerpo, pero más allá, de la vida. Estos dispositivos poseen tres características: son aparatos de acción continua, su efecto progresivo debe continuar una vez quitado, y son homeostáticos; es decir, cuanto más se resista más se siente, cuanto menos se resiste menos se sienten. En esta línea comienzan a aparecer los elementos que permiten un efecto en los comportamientos, la idea de continuidad, progresividad y sutileza en cuanto a la noción de flexibilidad y plasticidad-, que provocarán la modificación de las conductas, de manera perdurable. El procedimiento, el dispositivo puede instalarse, porque no molesta -el cuerpo puede adaptarse- sin ofrecer demasiadas resistencias.

En este sentido, nos interesa recuperar otro fragmento del taller que alude a lo analizado, Soledad continúa los comentarios de Flavia acerca del modo fragmentado de mirar los cuerpos por ahi lo pienso en el patio de la escuela y no necesariamente en las imágenes de un deportista de alto rendimiento, pero me pienso en el patio de la escuela, desde mis experiencias como profe de Educación Física; en todo mi esfuerzo por el que mis estudiantes puedan desarrollar sus habilidades motrices, y que los chicos puedan aprender a saltar, a correr, a lanzar, a reptar, a trepar-refiere a las habilidades motrices básicas- estamos pensando lo que en Educación Física podemos entender como habilidades motrices y también a desarrollar sus capacidades coordinativas y condicionales, que entran en juego también en el plano de lo pedagógico. Si nos pensamos como profes, este discurso y este enfoque se articula -para pensar nuestras clases de Educación Físicacon un discurso pedagógico; entonces existe un filtro pedagógico que va a dar lugar a la construcción del contenido, la decisión del contenido que voy a tener en cuenta y esto se sostiene de un término que ustedes nombran en el chat que es la metodologia, esta palabra cargada de sentido en la formación docente de Educación Física. Recuerdo en mis experiencias como estudiante [recupera una frase recurrente] que "un buen profe tiene que saber corregir, tiene que saber presentar buenas metodologias para que nuestros estudiantes aprendan", entonces en esta linea se produce este borramiento del que hablaba Flavia, en el sentido en que estamos mirando el cuerpo parcializado o fragmentado y no estamos incluyendo, por ahi, otros enfoques sobre cuerpo.

Cuando yo les pregunto a mis estudiantes de Didáctica de la Educación Física, en las primeras clases - a modo de trabajo intuitivo- ¿cómo enseñarian una medialuna o el lanzamiento de jabalina? lo que les pasaba a los chicos era que me respondian describiendo (los pasos) de la técnica. Aparecen las descripciones de las progresiones técnicas que nos van marcando o nos van mostrando un enfoque, como planteó Flavia, fragmentado. Fragmentado en espacio y en tiempo, porque también pienso que la "organización temporoespacial" es un contenido de la Educación Física. Pareciera que nosotros como docentes tenemos que poder incidir en la corporeidad de nuestros estudiantes y que ellos incorporen la orientación temporo-espacial. Hay esfuerzos de los y las profesoras de pensarnos de esta manera en las aulas. Y esto, lo que nos 
muestra es que hay una manera en la que se está mirando el cuerpo, una forma que entendemos como lenguaje común que no muestra pluralidad en cuanto a los enfoques ni tampoco a los cuerpos. Entonces cuando yo pienso en los planos y ejes para mirar los cuerpos, el borramiento del género se produce porque no tiene lugar. En un plano o en un eje corporal no hay lugar para la subjetividad.

\section{La pedagogización de la mirada del cuerpo.}

Esta forma de mirar el cuerpo, a partir de planos y ejes en el que la economía del esfuerzo, del tiempo y del espacio, fecunda el enfoque de la productividad del cuerpo y sus funciones, configuró la mirada de los cuerpos en Educación Física.

Es interesante pensar cómo esta forma de mirar el cuerpo se inscribe en el proyecto pedagógico moderno, como uno de los elementos técnicos para producir conocimiento.

La función escolar, a decir de Skliar y Téllez (2008) como dispositivo de la modernidad, ha logrado la transmisión cultural en las sociedades a partir de la construcción de los sistemas educativos, cuya intención es la educación de forma masiva e igualitaria, en el marco de las democracias modernas. En esta línea, el proyecto pedagógico como una forma de producir conocimiento, prefigura el orden y los flujos de "un" modo de conocer, ubicado como única forma de conocimiento válido: el conocimiento científico traducido en conocimiento pedagógico para toda la sociedad, a partir de la transmisión cultural - escolar.

La práctica pedagogizante de la enseñanza aparece como una función de regulación y reproducción del uso del espacio, del tiempo y de los discursos que circulan a fin de cumplir la tarea disciplinar específica.

En esta configuración resulta interesante recuperar otro elemento que es solidario a tales fines, aquello que podemos nombrar como la educación de la mirada. Siguiendo a Dussel (2009) la escuela fue el escenario en el que se produce la cultura de la imagen a través de la pedagogización de la mirada. Esta mirada construye la noción del espectador moderno, en el que se produce el distanciamiento entre el sujeto que mira y el objeto a ser mirado. En la educación visual promovida y planificada en y desde la escuela, ver se volvió equivalente a saber y a creer ("ver para creer"), en una articulación que sigue operando con firmeza en nuestras formas de conocer. No había mediación ni opacidad en el acto de ver; y las diferencias fueron ubicadas como anormalidades o desviaciones patológicas. Siguiendo a Boltanski (Dussel, 2009) a partir de estas técnicas se constituye el espectador moderno, que se suponía tendría al mismo tiempo una cierta imparcialidad -distancia entre la observación y la acción (refrenar los impulsos, intervenirlos por la reflexión)-, y también compromiso: esto es, una inversión emocional y afectiva que es necesaria para suscitar la afiliación política en la esfera pública; era el sujeto social, ciudadano, que los Estados requerían para sus naciones.

En esta línea, Dussel (2009) plantea que la pedagogía moderna tomó muchas formas visuales: desde láminas y libros, armarios de exposición, 
lecciones de objetos, excursiones, a lo que podríamos incluir, desde la Educación Física, las exhibiciones gimnásticas, las filas, las hileras y los balanceos, que responden en este sentido a una mostración de cuerpos ordenados. "Todas estrategias para educar los modos de ver de los escolares y los sentidos que debían construirse en torno a estas experiencias visuales" (Dussel, 2009 p. 185). La educación del cuerpo, siguiendo a Galak (2017) refiere a aquellas formas institucionalizadas de moverse que tienen por objeto el cuerpo y el movimiento. Conforman así, la educación corporal, los compendios de técnicas y prácticas corporales transmitidas culturalmente que se inscriben en proyectos históricos y políticos produciendo maneras de jugar, hacer gimnasia, formas de pararse, de moverse, -también de ser mujer y de ser varón- que demuestran aprendizajes sociales y colectivos, significativos para nuestra cultura. La Educación Física es la asignatura escolar encargada de estas cuestiones.

De acuerdo con González, S. y Andermann, J. (2006) el mostrar y el contar poseían grados similares de importancia, siendo elementos para la implementación de las "tecnologías visuales de la verdad", que buscaron estabilizar las formas y contenidos de la representación del mundo. En esta línea se inscribe lo que consideramos como mirada ortopédica para mirar el cuerpo de lxs escolares gestionada por la Educación Física, en su proceso de constitución como disciplina escolar.

Aparece aquí la noción de cuerpos en el espacio, de segmentaciones y de movimientos parcializados que se sostienen desde los saberes biomecánicos proporcionado por la ciencia moderna. Y lo que se entiende como un ordenamiento y una distinción esencial: "cuerpos de frente a". El movimiento humano era posible de ser estudiado, mirado, segmentado, educado. Siguiendo a Galak (2017) algunas estrategias utilizadas por el Estado -durante el período de los gobiernos peronistaspara esta pedagogización de los cuerpos, fue la de presentar a partir de filmografías y fotogramas, la educación de los cuerpos a través de la mostración. Esta sucesión de imágenes en movimiento y -de movimientos- construyeron, siguiendo a este autor, modos de hacer correctos y modos de ser, legitimados, "la difusión de una estética particular generalizada, o, lo que es lo mismo, una estética universalizada, percibida como particular" (Galak, 2017, p. 60).

A decir de Flores (2008) esta construcción moderna de conocimiento que la escuela proporcionaba y pedagogizaba, se asentó en pares dicotómicos: hombre/mujer, público/privado, heterosexualidad/homosexualidad, civilización/barbarie, blanco/negro, burgués/trabajador, productor/reproductor, etc., los cuales se encuentran sexualizados y jerarquizados,como parte del orden escolar. Ubicando, de acuerdo con Segato (2016) al hombre como Uno, y toda la otredad subordinada a éste. Por lo tanto, lo escolar, es un sistema que produce formas de conocer que naturaliza estas desigualdades. La transmisión cultural, ordena las posiciones para el varón y para la mujer, vinculando a éste con lo público, lo universal, lo racional, lo intelectual, lo productivo; mientras que a la mujer se la vincula con lo privado, lo particular, lo emocional, lo reproductivo, lo inestable y el cuerpo. 
Consideramos que la mirada ortopédica de los cuerpos se manifiesta en este orden escolar que la pedagogía establece como verdad, a partir de una serie esperada y medible de efectos sobre el sujeto, concatenados: el análisis del movimiento humano -a modo de espéculo- produce una subjetivación específica del cuerpo. A este respecto, las operaciones vinculadas con el ejercicio y la transmisión de las habilidades motrices y las técnicas deportivas, encuentran, en esta forma de mirar, una estrategia útil para transmitir, saber y desarrollar la motricidad. Este efecto permite la lectura de una motricidad analítica y ipor qué no técnica? en la que cierto modo de subjetividad no encuentra lugar. La mirada ortopédica da lugar a cuerpos con atributos específicos y recortados, da lugar a "un cuerpo biomecánico", proyectado desde las operaciones de ajuste que prefiguran la aplicación de las tecnologías de la política de los cuerpos en la modernidad.

Este modo específico de producir cuerpos, provoca un velamiento de las reproducciones desiguales en el orden escolar. A partir de la visión modelada por las ortopedias modernas de los agentes escolares, se produce un ordenamiento, entendido como el ordenamiento escolar - social genérico. Porque el foco de la mirada no se encuentra, ni en la significación de cuerpos sexuados, ni en la revisión de las estructuras disciplinares, sino en la producción objetiva de conocimiento. Esta ignorancia hacia los atributos que expresan y manifiestan la sexualidad de lxs cuerpxs, refuerza y re-actualiza el orden de género en los espacios escolares, consolidando un patio heteronormativo estacionado en las tradiciones homogeneizantes del proyecto clásico moderno.

Recuperando intercambios del taller, es ahi cuando empezamos a no tener herramientas para comprender esto. Y resulta que abora ESI es una ley ¿y cómo la vamos a desarrollar? ¿y qué está pasando? y por abisiento [expresa Soledad] que no tenemos herramientas para leer esos cuerpos porque hay un discurso que está predominando, que no da lugar a la subjetividad. Si yo pienso un cuerpo desde planos y ejes estamos reduciendo no sólo el concepto de cuerpo, que es plural y polisémico, sino que también estamos reduciendo las corporeidades con las que estamos trabajando, con las que intentamos encontrarnos en un acto educativo.

Noelia, en el chat hace una pregunta a raíz de lo que estábamos discutiendo ¿"repensar este discurso es repensar todo el contenido de la Educación Física Escolar? Flavia responde diciéndole que pensar en técnicas y en tecnologias corporales implica pensar en una alianza epistémica, entonces habria que desandar cuáles son los elementos que conforman esa alianza en la Educación Fisica, para ir repensando los discursos. Además las discursividades se transforman en prácticas y esas prácticas entrañan esas alianzas y por ahi las seguimos poniendo en acto y en las escuelas emergen diversidades corporales, diversidades subjetivas y esas emergencias nos da cuenta justamente que hay un discurso desfasado. Entonces yo (como docente) voy a insistir con que salte, salte, salte y quizás habria que revisar si el discurso es coherente o correspondiente a lo que emerge en la práctica. Pensar justamente los hilos epistémicos para ver de qué modo sostengo o sitúo mi práctica. Ahora, cuando yo opero desde tecnologías previas, opero el 
borramiento, la anulación, lo que en la ESI se trabaja como el silenciamiento. Pienso en cuerpos que se esfuerzan o que se fuerzan, para cumplimentar con una práctica que es la práctica aprendida y administrada en ciertos espacios y en ciertos momentos. Entonces quizás repensar esas alianzas sería como la propuesta, lo que nosotras estamos por ahi viendo.

\section{El cuerpo con atributos.}

Al planificar la charla incorporamos la perspectiva de derechos y la sexualidad desde aquello que la ESI nos propone, retornar o recobrar el cuerpo o lxs cuerpxs como una unidad de deseo y de placer, aquello que parece quedar afuera de las técnicas y mecanizaciones hegemónicas de lxs cuerpos. En este sentido, recuperamos el término atributo como la noción de repartir, asignar, designar para la tribu, lo que nos permite repensar estas nociones para reconocer las operaciones sobre el cuerpo y sus invisibilizaciones.

La intención de reconocer los atributos (invisibilizados) de los cuerpos, parte de repensar el sentido de atributo como las cualidades que sexualizan en términos de placer y no de hegemonías que definen el orden deseante de lo corporal. Si bien una cualidad o características, en términos de representación de lo corporal tiene múltiples atravesamientos y polisemias, interpretamos que el orden sobre el espacio corporal neutraliza los volúmenes que dan cuenta de una existencia erótica, irracional, impúdica, lujuriosa y terrenal.

El cuerpo sin atributos sería aquel que transporta e identifica todas las operaciones realizadas con la finalidad de los velamientos para designar y atribuir sentidos específicos a los cuerpos.

Mercedes expone en la charla: que la naturalizacion del binarismo sexogenero de la enseñanza, hace que se crea que existe una correspondencia en los sentires y deseos por la identidad biologica,...se hace pensar que las expresiones entre varones y mujeres y las formas del deseo son una sola $y$ binarias, creer que no habrá roces, ni toques, ni sensaciones y pensar la enseñanza desde la lógica heterosexual.

La ESI irrumpe con esta naturalización y obliga a mirar nuevamente lxs cuerpos para sacar las " anteojeras binaristas", cuando recuperamos las miradas sobre lxs cuerpos se torna necesario analizar las imágenes que participaron en nuestra formación docente. En la revisión de las imágenes aparece "el monigote", la esquematización de la figura humana por excelencia que remite a un icono de sentido común sobre lxs cuerpos. La iconografía del "monigote" y sus versiones de escolaridad inicial, primaria, secundaria y más, opera de imagen y escritura para enunciar al cuerpo, unario y monocultural.

Para tomar esta reflexión, Soledad cuenta que cuando estudiaba Educación Física, en una materia que en su momento se llamaba Anatomía Aplicada, les enseñaban a pensar y mirar el cuerpo en planos y ejes. Para poder explicar el cuerpo desde los planos, utilizaban un papel y una lapicera. Planos vertical, horizontal, sagital. Son conceptos que significan y tienen un sentido. Pensar los planos y ejes del cuerpo. Esto no 
aparece de la nada, hay toda una historia que fue construyendo todo un enfoque y todos toman este enfoque y hablamos un lenguaje común. Soledad se pregunta: ¿cómo se entiende porque?, ¿cómo ingresan en la formación docente y en la formación escolar?... Todo el esfuerzo porque mis estudiantes puedan desarrollar sus habilidades motrices y aprendizajes de las tareas coordinativas de la EF.

La bibliografía que encontramos de este enfoque motricista redunda en tal discursividad anónima y de borramiento de los atributos de la sexualidad y el deseo. Las imágenes muestran cuerpos fragmentados y distribuidos en espacios predeterminados, y la tarea de lxs docentes de EF empieza a centrarse en ayudar y conducir a sus estudiantes a mirar de ese modo. Tales procesos instalan en el espacio pedagógico de la EF las ortopedias corporales y operan en borrar la pluralidad de cuerpos y subjetividades.

El desfase que opera desde la teorización o modelos dominantes y la práctica real con cuerpos concretos en la $\mathrm{EF}$, hace y produce el hacer de la enseñanza de EF. El hacer se aboca en transformar lo real en aquello modelado y tallado por la teorización disciplinar. Es decir, la prescripción tan detallada y calculada para las prácticas de la enseñanza de la EF hace de su tarea algo modelado y tallado.

De pronto, y desde la ESI, nos indican que se piense y vea atributos de la sexualidad en un cuerpo segmentado en planos y ejes. La ESI desde su propuesta pone en evidencia que lxs cuerpos que saltan, corren y lanzan son cuerpos sexuados. ¿En qué momento, entonces, nuextrxs cuerpos dejaron de tener sexo?, o se supone que ¿el sexo no esta puesto en juego en ciertas actividades? nos preguntamos.

En una norma binaria y generizada de la enseñanza, aparece como extraño aquello por fuera de esa norma. Aparece lo "otro" como indisciplinado. Nos extraña el hacer del otro cuando no cumple con lo normalizado, con lo naturalizado, la clave de la naturalización está en dejar de ver, en darlo como lo que es, dejar de ser visto y transformar esa invisibilización en la pedagogía de intercambio en los espacios escolares. El surgimiento de una presencia "otra" aparece como la rareza, dice Mercedes. Dentro del sistema heteronormativo miro la rareza entonces y pienso ¿qué debo hacer para incluir?, lo que se transforma en una falsa igualdad.

Para poder pensar la modificación que se expone en la charla, debemos pensar en clave de derechos. La ESI como política de derechos interpela los mitos y falsas igualdades para acercarse a lo real que se manifiesta en las aulas y lxs espacios escolares, casi como los espacios sociales. Es necesario entender los enfoques que construyen nuestras miradas, las teorías que enraizan nuestras creencias y nuestro hacer. Revisar los contenidos heredados, algo que permite habilitar otras formas y herramientas para la enseñanza de la EF.

En las reflexiones que se entretejieron en la charla, aclaramos que esxs cuerpos siempre estuvieron allí, pero en la actualidad, la ESI nos interpela a dejar de silenciarlxs y de borrarlxs. Este guión hegemónico y dominante de la educación y la EF ya no puede seguir adelante sino que 
debe deconstruirse y modificarse en pos de aquellxs cuerpos que real y concretamente fueron segmentadxs y desgarradxs en partes. Aquello que históricamente construyó el sufrimiento de muchxs.

\section{¿Cómo habría que mirar los cuerpos, en una Educación Física que piense en clave de derechos?}

Ante tal pregunta aparece como necesaria la intención de "sexuar el monigote". Hasta el momento, y en este período de transición de prácticas y nuevos discursos con los que nos encontramos en la formación docente, la figura de "monigote", continúa apareciendo en los diseños de las distintas unidades curriculares, en la formación docente y también en los niveles de enseñanza inicial, primario y secundario.

El cuerpo/monigote, es aquel que protagonizó históricamente los planes de clase de Educación Física en las generaciones de '70, '80 y '90 en su sección de ilustraciones y que luego se fue actualizando a través de distintos elementos que conformaron las planificaciones de Educación Física en sus distintas versiones de organización: unidades didácticas, secuencias didácticas, etc. La noción de cuerpo monigote se puede reconocer en los propósitos que una secuencia didáctica ${ }^{7}$ puede utilizar para las estrategias de enseñanza del nivel primario, por ejemplo: "reconocer su esquema corporal a través de experiencias diversas que promuevan el conocimiento de sí mismo", incluso con la intención de promover las expresiones de lxs estudiantes a través de su "corporeidad". Este propósito se articula con una selección de contenidos recuperados del diseño curricular de Educación Física para este nivel: las partes del cuerpo, ¿qué puedo hacer con mi cuerpo?, realización de movimientos con los distintos segmentos corporales, ¿cómo realizo los movimientos y cómo lo hacen mis compañeros? ¿en qué me distingo de los demás? Estas nociones definidas en una posible planificación, delinean ciertos aprendizajes esperados: "identifica sus segmentos corporales para establecer semejanzas con los demás y reconocerse dentro de la diversidad", "actúa con seguridad al desempeñarse en diferentes actividades para proponer alternativas de realización" $^{8}$.

El monigote aún se pone de manifiesto, como el centro de la acción educativa ${ }^{9}$, a partir de la planificación a través de "competencias"10, modalidad propuesta a partir de los lineamientos de prioridades pedagógicas ${ }^{11}$ organizadas por la SPIyCE para el período 2015-2019, y que continúa por la situación de distanciamiento (DSPO).

La educación por competencias, en términos de Padilla Delgado presenta tres líneas en las que creemos que esta noción de cuerpo/ monigote y las operaciones de ortopedia y analitica del cuerpo se actualiza: "la corporeidad como manifestación global de la persona", "expresión y desarrollo de habilidades y destrezas motrices", "control de la motricidad para el desarrollo de la acción creativa”, que tiene como ámbitos de 
intervención pedagógica a "la competencia motriz, a la promoción de la salud y a la ludo-socio-motricidad" (Padilla Delgado et al., 2008) .

Estos conceptos que sostienen actualmente a las prácticas de la Educación Física no resuelven la concepción y representación del cuerpo/ monigote, tampoco promueven prácticas más justas sobre los cuerpos con atributos o cuerpxs sexuados.

La noción de corporeidad como la unidad de expresión y totalidad de existencia humana, "la condición de la presencia, participación y significación del hombre en el mundo" (Sergio, 1996), que se manifiesta ante una amplia gama de gestos, posturas, mímicas y acciones; y que siguiendo a Trigo Aza (1999) implica hacer, saber, comunicar, sentir, y querer; sólo pinta la cara de ese cuerpo al que la Educación Física pretende educar para "conocerlo, desarrollarlo, sentirlo y aceptarlo".

El monigote y las técnicas de movimiento específicas para diseñarlo, sigue siendo el eje de la enseñanza. Estas intenciones del paradigma motricista por superar el enfoque biomecánico de la Educación Física, o el deportivista, actualiza la mirada ortopédica sobre lxs cuerpos, ante la transposición didáctica que se realiza en las planificaciones de clase. Cumpliendo la función epistémica por la que se sostienen las disciplinas.Y lxs cuerpos vuelven a ser educados, se inscriben en un nuevo "proyecto corporal”, en términos de Scharagrodsky ${ }^{12}$, que pone su énfasis en la "conciencia motriz", en la "competencia motriz" ${ }^{13}$, en la psico-sociomotricidad a partir de la "acción motriz" ${ }^{14}$, pero de ninguna manera propone sexuar -en tanto darle el lugar del deseo (no hegemónico)- a este cuerpo.

\section{Consideraciones finales}

Ante la nueva agenda educativa - y didáctica- construida a partir de la implementación de la Ley Nacional de Educación 26.206, las demandas por transformar las aulas y desarrollar políticas inclusivas abordan la formación docente. Con la implementación del seminario de Educación Sexual Integral en la formación docente de Educación Física, las inquietudes sobre el qué hacer al respecto del género, se tornan recurrentes.

Ante la denuncia de una Educación Física generizada, desigual y en muchos casos misógina y machista. (Barra, 2016). El interés por modificar las prácticas, aparece ya sea en la producción pedagógica - didáctica o bien científica. Las preguntas en los patios y en las aulas, y en la formación docente -como también lo fue en este taller que recuperamos para su análisis- se relaciona con el quehacer de las clases. "¿Y cómo hacemos?" emerge con cierta inmediatez, la necesidad de cambiar las operaciones de la Educación Física. Aparecen las opciones de las clases mixtas, del intercambio de roles en los espacios de las danzas, en especial las folclóricas. Hay un interés de lxs docentes actuales y futuros, por la alternancia de la práctica de la Educación Física. 
En este sentido consideramos que la disciplina es la operacionalización de la episteme, la disciplina se encarga de mantener el orden epistémico a partir de sus instrucciones para el orden práctico. La disciplina, como producción de instrumentos y técnicas, ha generado las ortopedias que se transforman en "códigos disciplinares". Las ortopedias establecen de qué objetos se debe hablar, qué procedimientos se deben utilizar y hacia qué horizontes se deben dirigir. El modo operativo de la EF constituye esta función disciplinaria asignada, lo que provoca el efecto de la pregunta de ¿cómo operamos? y no la discusión sobre la EF en sí misma, que nos permita después pensar las operaciones.

Creemos que es el momento para que la EF transforme elementos conceptuales que hacen a su sustento epistemológico -la corporeidad y la motricidad-como contenido a desarrollar en las planificación de EF y en las vidas de las personas.

Analizar cómo está construido el saber de la EF, con qué tiene que ver, si ¿con las imágenes olímpicas o las escolares? y adonde está la vinculación con cada una de éstas, podría ser una línea para desplazar el eje de análisis disciplinar (operacional) hacia el epistémico (estructural) con respecto a la construcción de sentidos del saber de la EF. Que lxs participantes tengan mucho para decir sobre cuerpos en el que ya se aplicó la técnica, más que de espacios escolares, representaría un indicador, constituye una pista, de cuál ha sido la preocupación hasta el momento: sobre cómo ejecutar operaciones y efectos en los cuerpos, a la vez que mostrarnos las zonas por donde circula el Saber de la disciplina.

Como efecto, la mirada ortopédica produjo una escisión de la Educación Física con lo social. Este corte dificulta la posibilidad de verla como práctica.

¿Cómo hacer para que ese ojo que ha sido entrenado para situar esas técnicas en los cuerpos tenga algo para decir sobre los patios escolares? ¿Cómo hacer para que la mirada ortopédica pueda ver el cuerpo sexuado, el deseo?

Es significativo también, cómo al decir de lxs participantes de la charla, las descripciones de las imágenes olímpicas se acompañan de expresiones tales como superación, progreso, excelencia, constancia. Expresiones que dan cuenta de valoraciones morales que re-instalan permanentemente la función disciplinadora de la práctica técnica, en su dimensión de ajuste de la conducta. Lo que en términos de Foucault sería el saber pastoral de cómo experimentar y dar cuenta de sí mismos. Es el modelo civilizatorio, moralizante y de salud. Que conformó el código disciplinar que ordenó las prácticas de la pedagogía corporal en el siglo XIX y principios del siglo XX como proyecto corporal de la modernidad.

En los procedimientos de ajuste de las ortopedias lo que la disciplina debe garantizar es el campo anónimo de este proceso. Las ortopedias refuerzan el anonimato y el sujeto se pierde en él. Por ello es difícil pensar la sexualidad, porque no responde a lo que la disciplina solicita para la construcción anónima del campo: la producción de la técnica, de la regla, de la estructura. 
La preocupación disciplinar de la EF -que es la preocupación por las operaciones- es un discurso que la EF cree que es propio. Nos preguntamos si ese discurso ha sido funcional para velar el sentido de la EF como práctica que mantiene una relación epistémica específica. Ha sido un modo de producir veladamente la no preocupación por la estructura disciplinar, a decir de Foucault (Castro, 2011), el orden disciplinar, la disciplina como mecanismo de delimitación de los discursos. Nunca se discute su función, que en un punto es mantener la preocupación por la práctica.

¿Cómo iniciar la educación sexuada, o dejar de ignorar el género y lxs cuerpxs sexuados en EF? ¿Cómo reconocer las tramas conceptuales que reproducen estos borramientos?

Tal vez llegó el momento de sexuar el monigote. De producir atributos o formas que den paso a la sexualidad hasta que estas mismas sean obsoletas. Dibujar nuevas formas hasta que se transformen en viejas.

\section{Referencias Bibliográficas.}

Barra, E. (2016) Nueva mirada: El desafio de las clases de Educación Física Mixtas. Su impacto en la integración e inclusión escolar. (Trabajo Final para obtener el título de Licenciada en Educación). Universidad Empresarial Siglo 21. Buenos Aires. Argentina. Recuperado del repositorio de la Universidad Empresarial Siglo 21: https://repositorio.uesiglo21.edu.ar/bitstream/handle/ues21/13735 /BARRA\%20ELENA\%20GABRIELA.pdf?sequence=1\&isAllowed =y

Blázquez Sánchez, D. y Sebastiani Obrador, E. (editores). (2010). Enseñar por competencias en Educación Física. Barcelona: Editorial INDE.

Castro, E. (2011).Diccionario Foucault. Tema, conceptos y autores. Buenos Aires: Siglo Veintiuno.

Donda, C. (2014). Lecciones sobre Michel Foucault. Saber, sujeto, institución y poder político. Córdoba: Universitas/Jorge Sarmiento Editor.

Dussel, I. (2009). Escuela y cultura de la imagen. Los nuevos desafíos. Revista Nómadas, (30), 180 - 193. Universidad Central de Colombia. Recuperado de: https://www.redalyc.org/pdf/1051/105112060014.pdf

Flores, V. (2008). Entre secretos y silencios. La ignorancia como política de conocimiento y práctica de (hetero)normalización. Revista Trabajo Social, (18), $14-21$.

Foucault, M. (2002). Vigilar y castigar. Nacimiento de la prisión. Buenos Aires: Siglo Veintiuno Editores.

Galak, E. (2017). Educar (con) la mirada. Discursos politicos y sentidos estéticos sobre la cultura física en noticieros cinematográficos. En Gregorio Weigner. Escritos en su honor. Premio Gregorio Weigner a la investigación en Historia de la Educación, la Ciencia y la Cultura Latinoamericanas, 55 74. Buenos Aires: CLACSO.

González, S. y Andermann, J. (2006) Galerías del progreso. Museos, exposiciones y cultura visual en América Latina. Rosario: Beatriz Viterbo.

Hernández Moreno, J. (1993). La praxiología motriz ¿ciencia de la acción motriz? Estado de la cuestión. Revista Apunts Educación Física y Deporte, (32), 5 - 9. Instituto Nacional de Educación Física de 
Catalunya: https://hemeroteca.revista-apunts.com/apunts/articulos/32/ es/032_005-009_es.pdf

Ley $\mathrm{N}^{\circ}$ 26.206. Ley de Educación Nacional. Ministerio de Educación de la Nación. Diciembre 27 de 2006. Recuperado de: http://servicios.infoleg.g ob.ar/infolegInternet/anexos/120000-124999/123542/norma.htm

Ministerio de Educación de la Provincia de Córdoba. Dirección General de Desarrollo Curricular, capacitación y acompañamiento institucional. Secretaría de Educación,. Guías de Lectura Prioridades pedagógicas 2014-2019. Recuperado de https://www.igualdadycalidadcba.gov.ar/SIP EC-CBA/Prioridades/PrioridadesPedagogicas.php\#gsc.tab $=0$

Padilla Delgado, J., Dávila Sosa, M., Torres García, F., Escalante Pliego, C., González Narvaez (2008) Guia de Educación Física para la Educación Primaria. Subsecretaría de Educación Básica, Dirección General de Desarrollo Curricular, Subdirección de Educación Física. México: https:/ /efmexico.files.wordpress.com/2008/08/guia_primarias_piloto.pdf

Parlebas, P. (1981) Contribution à un lexique commenté en science de l' action motrice. París: INSEP.

Parlebas, P. (2009) La acción motriz. Punta de lanza de la Educación Física. Revista de la Educación Física: renovar la teoría y práctica, (113), 5-12. Recuperado de https://dialnet.unirioja.es/servlet/revista?codigo $=1162$

Rodríguez, N. (2015) Programa de Teoría de la educación fisica IV: Problemas teóricos y epistemológicos del campo disciplinar. Departamento de Educación Física, Facultad de Humanidades y Ciencias de la Educación, Universidad Nacional de La Plata. Recuperado de: http://www.memoria .fahce.unlp.edu.ar/programas/pp.8384/pp.8384.pdf

Ruiz Pérez, L. (1995). Competencia Motriz: Elementos para comprender el aprendizaje motor en la Educación Fisica Escolar. Colección Monografías sobre Ciencias de la Actividad Física y Deporte. Madrid: Editorial Gymnos.

Ruiz Pérez, L. (2004). Competencia Motriz, problemas de coordinación y deporte. Revista Educación, (335), 21 - 33. Recuperado de: http://www.r evistaeducacion.educacion.es/re335/re335_04.pdf

Ruiz Pérez, L. (2014). De qué hablamos cuando hablamos de competencia motriz. Revista Acción Motriz, (12), 37-44. Recuperado de: http://oa.up m.es/35394/

Salmerón Sánchez, M. (2010). Programación de aula por competencias básicas para la Educación Física en primaria. Revista Digital efdeportes, 14(140), Buenos Aires. Recuperado de: https://www.efdeportes.com/efd140/prog ramacion-por-competencias-basicas-para-educacion-fisica.htm

Sérgio, M. (1996). Epistemologia da motricidade humana. Cruz-Quebrada: Ediçôes Faculdade de Motricidade Humana - Universidade Técnica de Lisboa.

Segato, R. (2016). La guerra contra las mujeres. Madrid: Traficante de sueños.

Skliar, C. y Téllez, M. (2008). Conmover la Educación. Ensayos para una pedagogía de la alteridad. Buenos Aires: Noveduc.

Trigo Aza, E. (1999). Creatividad, motricidad y formación de colaboradores. Revista Apunts: Educación Física y deportes, (56), 113. Recuperado de: htt ps://dialnet.unirioja.es/servlet/articulo?codigo $=294698$ 


\section{Notas}

1 Recuperación de diálogos con docentes del ISFD “Juana Azurduy”, Posadas Misiones. El nombre de la institución y de lxs docentes son ficticios.

2 Proyecto de investigación que llevamos adelante en el marco de la convocatoria del Ministerio de Ciencia y Tecnología - CBA - para Grupos de Reciente Formación con Tutor -GRFT - 2018.

3 Nota de campo. Género y Educación Física, diálogos iniciales. En el marco de GRFT - 2018.

$4 \quad$ Al taller lo coordinamos tres docentes: Mercedes, Flavia, Soledad.

5 un cuerpo en tanto presente situado, que condensa las coordenadas sociohistóricas y las actualiza. Los atributos del cuerpo contienen a la sexualidad como expresión de la subjetividad.

6 Esta visión responde a la función de un cuerpo eficaz, que aumenta su fuerza de trabajo en términos de adaptación y disminuye su fuerza política en términos de decisión. (Donda, 2014)

7 Modalidad de planificación utilizada en Educación Física para los niveles primario y secundario.

8 Planificación anual de Educación Física, organizada en bloques y sesiones, para 1er grado de primaria, ciclo lectivo 2016/2017.

9 Guía de Educación Física para la Educación Primaria, propuesta realizada por la Secretaría de Educación Pública, Gobierno de México, 2008.

10 Las competencias básicas responden a un enfoque de currículum aplicado que prioriza aprendizajes considerados como "imprescindibles" para la vida diaria. Las que asumen mayores vínculos con la $\mathrm{EF}$, de acuerdo con algunos autores, son: la competencia en el conocimiento y la interacción con el mundo físico, y a competencia social y ciudadana. Para profundizar este tema se pueden ver los trabajos de Salmerón Sánchez (2010), Blázquez Sánchez y Sebastiani Obrador (2010).

11 Los lineamientos propuestos por la Subsecretaría de Promoción de Igualdad y Calidad Educativa - Córdoba, para el período 2014/2019 son: mejora en los aprendizajes de lengua, matemáticas y ciencias; mayor tiempo en la escuela y en el aula en situación de aprendizaje; buen clima institucional que favorezca los procesos de enseñanza y aprendizaje y más confianza en las posibilidades de aprendizaje de los estudiantes.

12 Término utilizado en la charla virtual "La perspectiva de género en la E.F y el Deporte”, organizada por la agrupación Deportes Malvinas.

13 Para profundizar este conceptos, ver los trabajos de Ruiz Pérez (1995, 2004, 2014).

14 Ver los trabajos de Parlebas (1981, 2009) y Hernández Moreno (1993). 